\title{
Theoretical Analysis of Ammonium-perchlorate Based Composite Propellants with RDX Containing Small Size Particles of Beryllium
}

\author{
Paulo Alexandre Rodrigues de Vasconcelos Figueiredo and Francisco Miguel \\ Ribeiro Proença Brojo \\ Universidade da Beira Interior
}

\section{Abstract}

Rocket engines have been developed for at least the last six decades. There is a need to improve the actual solid propellant grain for rocket engines through the addiction of metallic fuels in the mixture as well as the addiction of energetic binders to stabilize the combustion. The rocket industry expects the launchers to be reliable, to be faster, stable and to have longer times of operation for the most possible payload weight

Corresponding Author: Paulo Alexandre Rodrigues de Vasconcelos Figueiredo paulo.figueiredo@ceiia.com

Received: 26 November 2019 Accepted: 13 May 2020

Published: 2 June 2020

Publishing services provided by Knowledge E

(c) Paulo Alexandre Rodrigues de Vasconcelos Figueiredo and Francisco Miguel Ribeiro

Proença Brojo. This article is distributed under the terms of the Creative Commons

Attribution License, which permits unrestricted use and redistribution provided that the original author and source are credited.

Selection and Peer-review under the responsibility of the ICEUBI2019 Conference Committee.

\section{G OPEN ACCESS} (operational envelope). New propellants should have optimized ignition and combustion time rates reducing the possibility of negative oxygen balance thus reducing detonation process. Deflagration process should be optimized for best performance of the rocket. In this evolution, small quantities of explosives have been used in the propellant in order to increase the operational burning time, hence, the specific impulse. Adding metallic fuels such as aluminum, boron or beryllium on double based composite propellants and ammonium perchlorate are expected to increase the propellant density over chemical stability and aging resistance. The study of heterogeneous propellants containing large amounts of fine beryllium and ammonium perchlorate, it is necessary to understand the combustion products so to a proper evaluation of specific impulse, Mach number and mass flow of the mixture. In this study a mixture with nitramides (RDX - Cyclotrimethylene trinitramide) and ammonium perchlorate was analyzed with and without the addiction of small size particles of beryllium using a numerical algorithm. Therefore, this study relates the influence of beryllium in the performance parameters of ammonium perchlorate based composite propellants.

Keywords: Propellant, Rocket engine, RDX, Ammonium perclorate

Both aeronautical and aerospace industry are always looking for new propellants for rocket propulsion. The latest developments in solid propellant are the so-called green propellants as well as the introduction of metallic fuels on the grain of double based composite solid propellants. A need for new and improved binders and metal fuels such as aluminum [1] and titanium [2] are required for the increase of specific impulse. The specific impulse increases also when traditional aluminum powders change into 
small size particles such as nano aluminum [3]. Ultra-thin aluminum and titanium in solid propellants have also been studied achieving higher specific impulses [4-11].

The authors of [3] have verified that the size of aluminum particles influences the burning rate of propellants. They have developed a mathematical model of the ignition and burning rate of metal fuels on the surface of a propellant, concluding that there is an increase in the burning rate and a decreased dependence on the pressure resulting in a specific impulse loss minimization.

In [12], it was verified a better performance in a dual oxidizer AP/RDX with ultra-thin aluminum in solid propellants at sub-atmospheric pressures due to aluminum influence. The author mentioned that propellants contains a double-based oxidant ammonium perchlorate and nitramides (RDX and $\mathrm{HMX}$ ) and up to $20 \%$ aluminum powder are very high promising propellants. The increased specific impulse is caused by the partial exchange of ammonium perchlorate of AP by HMX/RDX reducing the danger of hydrogen chloride from the combustion products into the environment.

During combustion of the propellant at sub-atmospheric pressures, the solid layers are longer and more distant from the surface which results in a reduction of heat flow of the flame on the surface. The burning rate is influenced by the aluminum particle size. Aluminum defined as an ultra-fine Aerogel has a thermal conductivity is much lower than the thermal conductivity of aluminum at micro scale.

In [13] it was studied the characterization of thermochemical solid propellant characteristics alongside with combustion behavior for nitramides, concluding that composite propellants with fuel in the matrix generated better performances than those without metal fuels. A study regarding thermal decomposition of nitramides with nitroglycerine was performed in [14], concluding that the combustion products performance was higher due to nitroglycerine. However, when adding nitrocellulose, the combustion chamber temperature was lower. In [15], it was initiated a study aimed to understand the recent progress in modeling of composite solid propellants. In this study they can see three areas of particular interest, first, the numerical modeling of pre flame using kinetic mechanisms. Second, the development of modeling to generate the geometrical distribution of particles simulating a heterogeneous propellant. Third the calculus process using the effect of the diffusion flame combustion critical for AP / hydrocarbon in solid propellants.

The parameters of RDX combustion zones at different pressures and initial temperature were studied in [16]; in this study were found two combustion zones, the first, under a basic regime $\mathrm{P}>0.1 \mathrm{MPa}$ and a second one under a basic procedure when $\mathrm{P}<=0.1 \mathrm{MPa}$. They concluded that both processes were active on a wide area in the 
gas phase reaction. In both cases was monitored a high heat release. It was also found that the dominant process was vaporization at low pressures and that the role of the exothermic thermal decomposition increased rapidly with the increase of pressure. The author of [17] studied the condensed combustion products of aluminized propellants as well as the effects of nitramides, and the bonding of aluminum and the combustion efficiency of the combustion. The author used two nitramides with different sizes (RDX and $H M X)$. He concluded with this study that, despite the burn rates are comparatively identical, with HMX particles in propellant E-12 (mixed with aluminum) the particle size is approximately 1.5 times wider than the ones of the RDX propellant $\mathrm{R}$.

The propellant RDX is characterized by a more severe agglomeration, the size and the agglomeration and mass are higher, and aluminum complete combustion is lower. The reaction of the RDX is initiated at a lower temperature, this leads to a faster oxidation of aluminum in the condensed phase of the heterogeneous system, which results in retention of the pellet surface. During the agglomeration of combustion, the resulting oxidation of aluminum is partially retained in the agglomerate due to substitution of aluminum oxide. The agglomeration of the mass distribution varies slightly within the range of the parameters studied despite the significant variation in the complete combustion of the aluminum.

Both beryllium boron and magnesium have been considered as potential candidates to replace aluminum with higher performance in solid propellants by other related studies [18]. The effects of incrementing particles $(5 e-6 \mu \mathrm{m})$ of boron in ammoniumbased composite solid propellant with RDX were identified although it is known the hazards of using either boron or beryllium.

The objective of this study is to use a combustion model for the aero thermochemistry of a composite solid propellant with and without the addition of beryllium (as metallic fuel) and to achieve a comparative study of combustion products as well as characteristic properties including flow mass, physical properties, specific impulse using beryllium as metal fuel.

\section{Theoretical Background}

Ideal rocket motors are based on the assumptions and fundamental equations [19].

1. The combustion products are homogeneous and invariant in composition;

2. The combustion products obey the perfect gas law;

3. The specific heats of the gas do not vary with pressure or temperature; 
4. The flow is assumed to be on-dimensional, steady and isentropic;

5. All kinds of fluid are gaseous. Any condensed phase (solid or liquid) adds a negligible;

6. There are no heat transfer at the shell of the rocket, (adiabatic flow);

7. There is no appreciable friction and boundary layer effects are ignored.

8. There are no shock waves or discontinuities in the flow in the nozzle.

9. The flow of the propellant is firm and constant, the expansion of the working fluid is steady and uniform, without vibrations.

10. Transient effects are neglected;

11. All the exhaust gases leaving the nozzle have a directed axial speed;

12. The gas velocity, pressure, temperature and specific mass are uniform to the normal axis of the nozzle;

13. The chemical equilibrium is stabilized within the combustion chamber.

This work considers the stabilization of working condition so to analysis the structure of solid composite propellant. The thrust was assumed to be $\mathrm{F}=50 \mathrm{kN}$. Nozzle parameters such as exhaust velocity, specific impulse, mass flow, areas, etc. were performed according to references [18-21]. The oxygen balance defined by Venugopal Thottempud [22] as the lack or excess of oxygen at a certain compound needed to transform all carbon atoms into carbon dioxide and hydrogen compounds in water. The oxygen balance can be obtained using Dalton's law $[4,5,19]$ as:

$$
P=\frac{R_{A} T}{V_{A}}+\frac{R_{B} T}{V_{B}}+\frac{R_{C} T}{V_{C}}+\cdots \frac{R_{n} T}{V_{n}}=\frac{R^{\prime} T}{M V_{\text {mix }}}
$$

The Free Gibbs energy can be estimated using [18, 19, 21];

$$
\begin{gathered}
\frac{d\left[A_{i}\right]}{d t}=\left(a_{i}^{\prime} a_{i}\right) K_{f} \prod_{j=1}^{n}\left[A_{j}\right]_{j}^{a}+\left(a_{i} a_{i}^{\prime}\right) K_{b} \prod_{j=1}^{n}\left[A_{j}\right]_{j}^{a^{\prime}} \\
\prod_{j=1}^{n} n_{A J}^{\left(a^{\prime} j-a j\right)}=K_{p}\left(\frac{p}{n}\right)^{\sum_{j}\left(a^{\prime} j-a j\right)} \\
K_{p}=e^{\left(\frac{A G^{0}(T)}{R_{0} T}\right)}
\end{gathered}
$$


Both molar enthalpy and the variation of the stoichiometric mixture ratio were calculated as [18]

$$
\begin{gathered}
n=\sum_{j=1}^{j=m} n_{j} \\
\Phi_{s} \frac{\mathfrak{M}_{\text {fuel }}\left(\sum_{i} I V I\right)_{\text {oxidizer }}}{\mathfrak{M}_{\text {oxidizer }}(-1)\left(\left(\sum_{i} I V I\right)_{\text {fuel }}\right)}
\end{gathered}
$$

Both chamber temperature and enthalpy variation can be obtained using [18]

$$
\begin{gathered}
\Delta H=\sum_{j} b_{j}\left[\left(q_{f}^{T_{S}}\right)_{j}+\int_{T_{S}}^{T_{C}}(C p)_{j} d t\right]-\sum_{i} a_{i}\left[\left(q_{f}^{T_{S}}\right)_{i}+\int_{T_{S}}^{T_{C}}(C p)_{i} d t\right] \\
T_{C}=T+\frac{100+\left[\Delta H^{\prime}\right]}{\left|\Delta H^{\prime}\right|+\left|\Delta H^{\prime \prime}\right|}
\end{gathered}
$$

The heat formation and constant pressure was obtained in accordance based on [22] and thermochemical data properties were obtained from [23].

Two considerations for a proper analysis assumes that oxygen balance must be closed to zero for total propellant consumption with less probability to form free radicals since too negative will cause detonation but too positive will cause a weak deflagration and stoichiometric mixture ratio [9] should be between 0.4 and 5 .

\section{Results and Discussion}

Table 1 are presented the formulation working parameters with and without beryllium. Mixtures with different contents of AP+RDX (case 1) and AP+RDX+Beryllium (case 2) were tested. The composition varies by replacing AP by RDX or AP by RDX or beryllium. The best mixture for mixture 1 , verified that the best performance occurred when $A P=61 \%$, and $\mathrm{RDX}=39 \%$, for case 2 the best mixture was verified to be for $\mathrm{AP}=47 \%$, Beryllium $=17 \%$ and $\mathrm{RDX}=36 \%$.

Considering performance parameters, for mixture 1 the mass flow rate is $23.6 \mathrm{~kg} / \mathrm{s}$ while for mixture 2 a total of $21.32 \mathrm{~kg} / \mathrm{s}$ was verified. The specific impulse for mixture 1 was verified to be $216.4 \mathrm{~s}$ while for mixture 2, $239.18 \mathrm{~s}$ was verified. Mach number decrease from mixture 1 (2218) to 2200 (mixture 2).

Figure 1 and Figure 2 present oxygen balance varying with specific impulse for mixture 1 and 2 . As it can be seen a higher specific impulse can be seen in mixture 2 as well as instabilities in the combustion through the oxygen balance.

Figure 3 and 4 shows the Mach number varying with specific impulse, mixture 1 shows a maximum value of 2.218 while mixture 2 shows 2.200 . Several discontinuities can be 
TABLE 1: Working parameters with and without Beryllium

Oxygen balance
Combustion chamber temperature $[\mathrm{K}]$
Specific impulse $[\mathrm{s}]$
Mass flow $[\mathrm{kg} / \mathrm{s}]$
Throat temperature $[\mathrm{K}]$
Specific consumption $[\mathrm{kg} / \mathrm{kW}]$
Explosion pressure $[\mathrm{Pa}]$
Explosive power $[\mathrm{kW}]$
Chamber pressure $[\mathrm{Pa}]$
Mach number

\begin{tabular}{|c|}
\hline$R D X+A P$ \\
\hline 12.34 \\
\hline 2548.2 \\
\hline 216.4 \\
\hline 23.6 \\
\hline 2302.8 \\
\hline 0.0046 \\
\hline $2.65 E+11$ \\
\hline 119360.0 \\
\hline 952979.0 \\
\hline 2.218 \\
\hline
\end{tabular}

RDX+AP+Beryllium

8.22

2942.2

239.18

21.32

2658.3

0.0042

2.87E+11

128980.0

951470.0

2.200

seen in Figure 2 due to lack of binders to stabilize the mixture, however more studies are required.

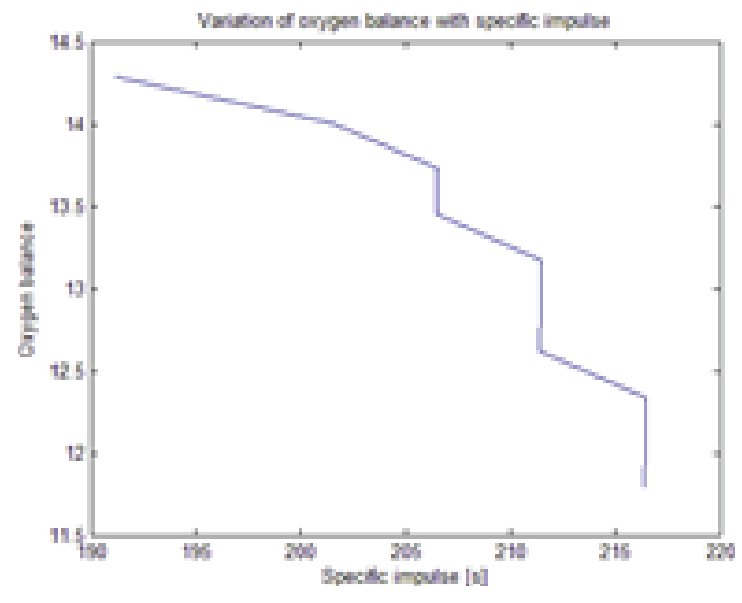

Figure 1: Oxygen balance (mixture 1)

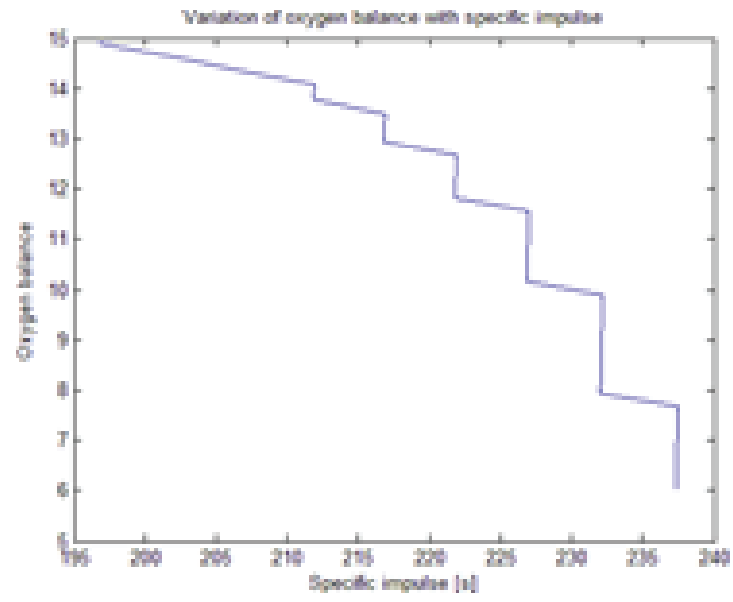

Figure 2: Oxygen balance (mixture 2) 


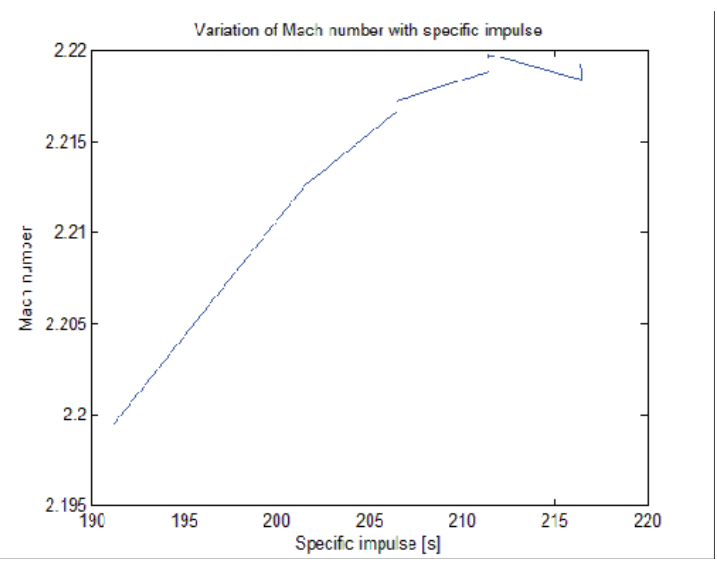

Figure 3: Mach number with Isp (mixture 1)

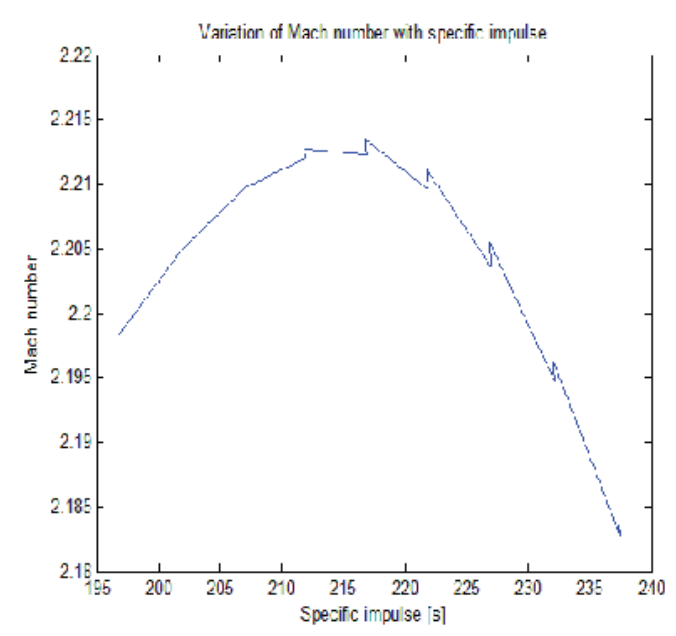

Figure 4: Mach number with Isp (mixture 2)

\section{Conclusions}

The effects of using beryllium as metal fuel in composite solid propellant rocket were estimated and performance parameters were obtained. After obtaining the best mixture for both cases, it was found that the mixture 1 (without beryllium) reaches a specific impulse of 216.44 seconds, while for second mixture an specific impulse of 239.8 seconds was verified, meaning that by introducing beryllium in the propellant an increase of $10,7 \%$ on the specific impulse was verified.

This study shows the theoretical behavior of beryllium as metal fuel for solid composite propellant rockets. As for future works, green propellants should be verified in order to minimize hazard characteristics such as paraffin and liquid oxygen. 


\section{Acknowledgments}

The current study was funded in part by Fundação para a Ciência e Tecnologia (FCT), under project UID/EMS/00151/2013 C-MAST, with reference POCI-01-0145-FEDER007718.

\section{References}

[1] S. Gallier, and F. Godfroy. Aluminium Combustion Driven Instabilities in Solid Rocket Motors. Journal of Propulsion and Power 25.2 (2009): 509-521.

[2] M. Stephens, E. Petersen, R. Carro, D. Reid and S. Seal. Multi-parameter Study of Nanoscale $\mathrm{TiO} 2$ and $\mathrm{CeO} 2$ Additives in Composite AP/HTPB Solid Propellants. Propellants, Explosives and Pyrotechnics 35 (2010): 143-152.

[3] V. Babuk, I. Dolotkazin, A. Gamsov, A. Glebov, L. Deluca and L. Galfetti. Nanoaluminium as Solid Propellant Fuel. Journal of Propulsion and Power 25.2 (2009): 482- 489.

[4] M. Li, F. Li, R. Shen and X. Guo. Molecular Dynamics Study of the Structures and Properties of RDX/GAP Propellant. Journal of Hazardous Materials 186 (2011): 20312036.

[5] M. Beckstead, K. Puduppakkam, P. Thakre and V. Yang, V. Modeling of Combustion and Ignition of Solid Propellant Ingredients. Progress in Energy and Combustion Science 33 (2007): 497-551.

[6] T. Zhou and F. Huang. Effects of Defects on Thermal decomposition of HMX via ReaxFF molecular dynamics simulations. J. Phys. Chem. B 115 (2011): 278-287.

[7] M. Beckstread. Solid Propellant Combustion Mechanisms and Flame Structure. Pure Applied Chemistry 5.2 (1994): 297-307.

[8] A. Tahsini and M. Farshchi. Thrust Termination Dynamics of Solid Propellant Rocket Motors. Journal of Propulsion and Power 23.5 (2007): 1141-1142.

[9] A. Ulas, Y. Lu and K. Kuo. Ignition and Combustion Characteristics of RDX-Based Pseudopropellants. Science and Technology 175 (2003): 695-270.

[10] W. Cai, P. Thakre and V. Yang. A Model of AP/HTPB Composite Propellant Combustion in Rocket Motor Environments. Combustion Science and Technology 180 (2008): 2143-2169.

[11] V. Arkhipov, M. Gorbenko, T. Gorbenko and L. Savel'eva. Effects of Ultrafine Aluminium on the Combustion of Composite Solid Propellants at Subatmosfetic Pressures. Combustion, Explosion and Shock Waves 45.1 (2009): 40-47. 
[12] W. Li. Combustion Behavior and Thermochemical Properties of RDX-Based Solid Propellants. Propellants, Explosives, Pyrotechnics 23.3 (1998): 128-136.

[13] W. Jing, Z. Dang and G. Yang. The Thermal Decomposition Behavior of RDX-Base Propellants. Journal of Thermal Analysis and Calorimetry 79.1 (2005): 107-113.

[14] M. Beckstead. Recent Progress in Modeling Solid Propellant Combustion. Translated from Fizika Goreniya i Vzryva 42.6 (2006): 4-24.

[15] B. Chen, Z. Xia, L. Huang, J. Hu. Ignition and combustion model of a single boron particle. Fuel Processing Technology, 165 (2017), 34- 43.

[16] M. Barrére, A. Jaumotte, D. Veubere, J. Vanderkersckhove. Rocket Propulsion. Elsevier Publishing Company (1960).

[17] G. Sutton. Rocket Propulsion. John Wiley \& Sons (2001).

[18] http://www.nakka./rocketry.net/techref.html, consulted at August (2012).

[19] N. Kubota. Propellants and Explosives - Thermochemical Aspects of Combustion. John Wiley \& Sons (2007).

[20] V. Thottempudi, H. Gao and J. Shreve. Trinitromethyl-substituted 5-nitro- or 3azo- 1,2,4-triazoles: Synthesis, Characterization and Energetic Properties. Journal of American Chemistry Society 133.16 (2011): 6464-6471.

[21] http://www.cache.fujitsu.com/mopac/Mopac2002manual/table_of_heats.html, consulted January (2018).

[22] http://kinetics.nist.gov/janaf/, consulted September (2018).

[23] Figueiredo, P. Theoretical analysis of an AP, RDX, Boron propellant. MSc Thesis, Universidade da Beira Interior, Covilhã, Portugal (2012). 